\title{
Effect of FDM Printing Parameters on the Properties of Carbon Fiber Reinforced PET-G Composite
}

\author{
Kaushal Sharma ${ }^{1}$, J. Raghavan ${ }^{2}$ \\ Composite Materials and Structures Research Group and Department of Mechanical Engineering \\ University of Manitoba, Winnipeg, MB, Canada R3T5V6 \\ sharmak2@myumanitoba.ca1; Raghavan.Jayaraman@umanitoba.ca²
}

\begin{abstract}
Fused Deposition Modelling (FDM) is the one of the most widely used additive manufacturing processes because of its low cost, simplicity of the process and capability to use a broad range of thermoplastic materials. However, the mechanical properties of printed material are inferior to those manufactured by other methods such as extrusion, compression molding, and injection molding. While past studies have focused on the effect of FDM parameters on the properties of many polymers, such studies on composites are very limited. Hence, the objective of this research is to develop this knowledge by studying carbon fiber reinforced PET-G polymer. The effect of the four print parameters namely, infill orientation $\left(45^{\circ} /-45^{\circ}, 0^{\circ} / 90^{\circ}\right)$, layer thickness $(0.1 \mathrm{~mm}, 0.2 \mathrm{~mm}, 0.3 \mathrm{~mm})$, nozzle diameter $(0.3$ $\mathrm{mm}, 0.4 \mathrm{~mm}, 0.5 \mathrm{~mm}, 0.6 \mathrm{~mm})$ and print temperature $\left(240^{\circ} \mathrm{C}\right.$, $250^{\circ} \mathrm{C}, 260^{\circ} \mathrm{C}$ ) on the tensile strength and modulus was studied. Changing infill orientation from $45^{\circ} /-45^{\circ}$ to $0^{\circ} / 90^{\circ}$ at $250^{\circ} \mathrm{C}$ resulted in increase in the tensile strength from 44.1 $\mathrm{MPa}$ to $47.3 \mathrm{MPa}$ and in the modulus from $4.3 \mathrm{GPa}$ to $4.9 \mathrm{GPa}$ as the carbon fiber gets oriented along the print direction. Increase in nozzle temperature from $240^{\circ} \mathrm{C}$ to $260^{\circ} \mathrm{C}$ with 0.4 $\mathrm{mm}$ nozzle and $0.3 \mathrm{~mm}$ layer height increased the tensile strength from 31.7 MPa to 43.48 MPa. High temperature leads to better flow and adhesion of two layers. Lowering the layer height from $0.3 \mathrm{~mm}$ to $0.1 \mathrm{~mm}$ at $0.4 \mathrm{~mm}$ nozzle diameter and $250^{\circ} \mathrm{C}$, increased the modulus from 4.7 to $6.2 \mathrm{GPa}$.
\end{abstract}

Keywords-Fused Deposition Modelling, Carbon reinforced PET-G, Tensile Properties, Compression moulding

\section{INTRODUCTION}

Additive Manufacturing has the ability to manufacture complex structures with high precision and less waste than other conventional manufacturing techniques such as joining, machining and moulding. Among available 3D printing techniques Fused Deposition Modelling (FDM) is the most commonly used process because of its low cost, simplicity of the process and capability to use broader range of thermoplastic materials; besides, it doesn't require any specific tooling. FDM (also known as Fused Filament Fabrication
$(\mathrm{FFF})$ ) is an extrusion-based additive manufacturing technique, which was patented by Stratasys around 25 years ago to manufacture parts by depositing semi-molten thermoplastics layer by layer over a printing platform [1]. FDM printed parts have application in electronics [2], aerospace [3], biomedical [4-5], automobile [6], construction [7-10], textile [11-12], toy industries [13].

PLA and ABS are commonly used filaments and extensive research has been done to characterize the mechanical properties of these material as a function of printing process parameters. PLA is most used material due to its low cost, less offensive odor, processability at lower temperature and no heated-bed requirement which makes it easy to print and results in nice detailed parts [20]. ABS is known for more durability and functional parts as it has more strength and higher glass transition temperature than PLA. Dawoud et al. [14] recorded a tensile strength of $34.3 \mathrm{MPa}$ and flexural strength of $63.8 \mathrm{MPa}$ and FDM printed parts were able to achieve $91 \%$ tensile strength of injection moulded specimens. ABS generate more toxic fumes than PLA, which offsets its attractiveness of better functionality than PLA [18]. Mechanical properties of PLA and ABS, achieved by the optimizing the print parameters, are far less than the strength of $100 \%$ dense material. Void formation and poor layer adhesion between the printed layers impair the mechanical properties of the FDM printed composites[20].

Reinforcing the pure resin with reinforcement, required properties can be achieved. Reinforcements like glass fiber [21], carbon fiber [22-23] and silicon carbide whiskers [25], as well as expandable microspheres have been used in PLA and ABS[20]. The properties of reinforced composites depend upon the fiber aspect ratio, fiber content, and fiber orientation [26] . Printing of very complex parts is not possible with continuous fiber composites. Specimen manufactured with $15 \%$ discontinuous short fiber reinforced PLA reported the tensile strength of $53.4 \mathrm{MPa}$ and modulus of $7.54 \mathrm{GPa}$ [23]. 
With the addition of reinforcement, printing of thermoplastics becomes challenging and in order to realize the highest mechanical properties it is important to optimize the print parameters, which has not received much attention in the past. Print parameters that can be optimized are layer thickness, nozzle diameter, infill pattern, build orientation, raster angle, and extrusion rate of the composites. PET-G is known to have the blend of the best of the properties of both PLA and ABS and it emits low odor due to low volatile organic compounds (VOC's) generation and less nanoparticle emissions during printing [15]. It also has a higher glass transition temperature than PLA. Being a new material PET-G needs careful tuning and optimization of different print parameters to yield smooth printed parts with lower surface roughness and higher mechanical properties. Abouzaid et al characterized the effect of extrusion temperature on the mechanical properties of the copolyester but effect of other print parameters is not discussed in the literature [16]. No research has been reported on FDM of carbon reinforced copolyester and on optimization of print parameters on mechanical properties. In this research, the effect of the four print parameters, namely raster angle, extrusion temperature, nozzle diameter and layer height on the mechanical properties of the carbon reinforced PET-G was studied. The mechanical properties of carbon fiber reinforced PET-G determined as a function of various print parameters were compared with those of compression molded specimens to determine the optimal parameters.

\section{EXPERIMENTAL DETAILS}

\subsection{Material, Equipment, and Printed Specimen}

Composite filament (ColorFabb XT-CF20), $1.75 \mathrm{~mm}$ in diameter and consisting of PET-G polymer matrix and $20 \% \mathrm{Vf}$ of milled carbon fiber reinforcement, was purchased from ColorFabb. This carbon reinforced composite was printed using Prusa i3MK3 FDM Printer, equipped with E3D hardened nozzle to avoid the abrasive wear of the nozzle caused by the carbon fiber. Tensile testing of printed specimens was done, as per ASTM D638 standard [29] using MTS testing machine fitted with the extensometer, at the rate of $5 \mathrm{~mm} / \mathrm{min}$. Nikon's LV100 optical microscope was used to analyze the interlayer bonding and fiber orientation. Image of the printed samples captured by Nikon's DS-Fil camera was analyzed using NIS- Elements Basic Reserarch-3.0 software. The tensile test specimen, with dimensions as per ASTM D638 was designed using Solidworks 2015 and exported into Prusa Slicer2.0 in STL format. Selected input process parameters assigned to each STL file were used to slice the specimen using the Prusa slicer and the resulting G-code was exported to the FDM printer.

\subsection{Design of experiments}

The focus of this research was to optimize the print parameters to maximize the mechanical properties and there are ten print parameters that can be varied using the slicing software. Six parameters were maintained constant, four parameters, tabulated in Table 1, were varied. Rectilinear pattern was chosen to enable $100 \%$ infill density with 3 perimeters. The bed temperature was chosen to be $70{ }^{\circ} \mathrm{C}$ to enable better adhesion of the extruded material to the bed while printing. The minimum nozzle diameter was fixed at $0.3 \mathrm{~mm}$ since any diameter less than that resulted in clogging. Filament manufacturer recommends the printing temperature between $240{ }^{\circ} \mathrm{C}$ to $260{ }^{\circ} \mathrm{C}$ for this material. Hence, the extruding temperature for this study was varied in this range at $240{ }^{\circ} \mathrm{C}$, $250{ }^{\circ} \mathrm{C}$ and $260{ }^{\circ} \mathrm{C}$. Layer height is the height of each successive layer of material being deposited by the extrusion nozzle. Layer height less than the nozzle diameter would result in printed layers being compressed while that equal to or higher than the nozzle diameter would result in no pressure being applied to the printed layers. Since the former is required for better bonding between the layers, layer height in the range of 0.1 to $0.3 \mathrm{~mm}$ was used. Since the reinforcement fibers are likely to get oriented along the print direction due to shear flow of the matrix, orientation of the raster angle with respect to specimen axis (i.e. loading axis) is likely to influence the properties. Moreover, the amount and the orientation of defects (i.e. void space between layers) are also likely to change. Hence, raster angle was varied from $0 / 90^{\circ}$ to $\pm 45^{\circ}$. A total of 36 sets of print parameters were used to print the specimens.

Table 1. Variable Process Parameters

\begin{tabular}{|c|c|}
\hline Process Parameter & Values \\
\hline Raster Angle & $0^{\circ} / 90^{\circ}, 45^{\circ} /-45^{\circ}$ \\
\hline Temperature $\left({ }^{\circ} \mathrm{C}\right)$ & $240,250,260$ \\
\hline Layer Height $(\mathrm{mm})$ & $0.1,0.2,0.3$ \\
\hline Nozzle Diameter $(\mathrm{mm})$ & $0.3,0.4,0.5,0.6$ \\
\hline
\end{tabular}

\section{RESULTS \& DISCUSSION}

\subsection{Effect of raster angle}

Raster angle is the direction of the deposition of material to fill the interior part relative to the $\mathrm{X}$ axis of the build table, which is aligned with respect to the axis of the specimen (i.e. loading direction). Two type of rasters, commonly used are $0 \% / 90^{\circ}$ (layers having $0^{\circ}$ and $90^{\circ}$ alternatively) and $45^{\circ} / 45^{\circ}$ ( layers having $45^{\circ}$ and $-45^{\circ}$ alternatively). To reduce the number of experiments this effect was tested only for $0.4 \mathrm{~mm}$ nozzle and at $250{ }^{\circ} \mathrm{C}$ temperature and the one which resulted in higher strength was used for the remaining experiments. Optical 
images of the printed samples are shown in Figures 1 and 2 for the two raster angles. Orientation of the carbon fibers along the print direction is clearly observed in these images. Changing the orientation from $45 \%-45^{\circ}$ to $0 \% / 90^{\circ}$ the ultimate tensile strength increases from $44.1 \mathrm{MPa}$ to $47 . \mathrm{MPa}$ and modulus from 4.3 GPa to $4.9 \mathrm{GPa}$ as shown in Table 2. Assuming that the void content is same for both raster angles, the increase in properties for $0 \% / 90^{\circ}$ with respect $\pm 45^{\circ}$ would be due to orientation of carbon fiber (that gets oriented along the print direction) with respect to the loading direction.

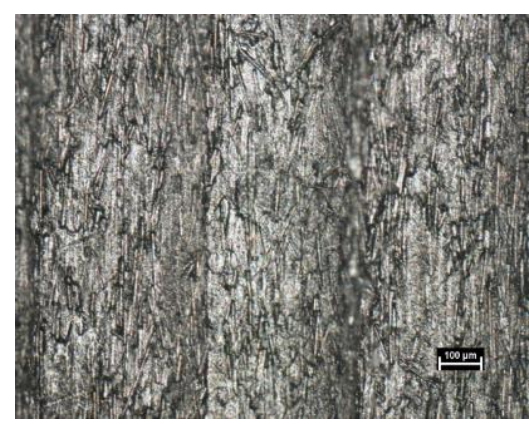

Fig $1.0^{\circ} / 90^{\circ}$

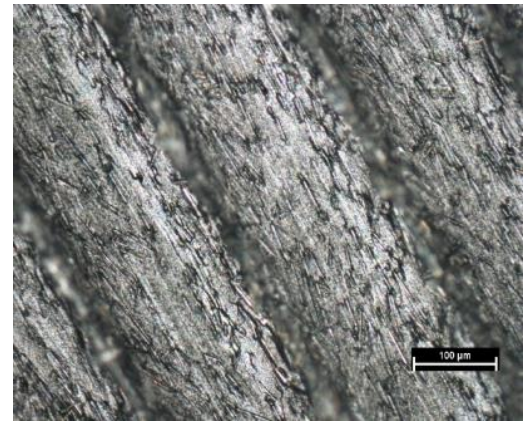

Fig 2. $45^{\circ} / 45^{\circ}$

Table 2. Effect of Raster Angle at $250^{\circ} \mathrm{C}$ and using $0.4 \mathrm{~mm}$ Nozzle Diameter

\begin{tabular}{|c|c|c|c|c|}
\hline Test & $\begin{array}{c}\text { Infill } \\
\text { Directi } \\
\text { on }\left(^{\circ}\right)\end{array}$ & $\begin{array}{c}\text { Layer } \\
\text { Thickn } \\
\text { ess } \\
(\mathrm{mm})\end{array}$ & $\begin{array}{c}\text { Tensile } \\
\text { Strength } \\
(\mathrm{MPa}), \\
\left(\mathrm{S} . \mathrm{D}^{*}\right)\end{array}$ & $\begin{array}{c}\text { Modulus(GPa), } \\
\left(\mathrm{S} . \mathrm{D}^{*}\right)\end{array}$ \\
\hline 1. & $\begin{array}{c}45^{\circ} /- \\
45^{\circ}\end{array}$ & 0.30 & $44.1(0.32)$ & $4.3(0.062)$ \\
\hline 2. & $0^{\circ} / 90^{\circ}$ & 0.30 & $47.3(2.8)$ & $4.9(0.270)$ \\
\hline
\end{tabular}

*Standard Deviation

\subsection{Effect of Layer Height}

The effect of layer height on the modulus and strength are shown in Figures 3 and 4 respectively for various nozzle diameters (N.D.) and print temperature. The tensile modulus and the tensile strength of the composite increased when the layer height is decreased from $0.3 \mathrm{~mm}$ to $0.1 \mathrm{~mm}$ for ND greater than $0.3 \mathrm{~mm}$ and at all three temperatures. If the diameter of the printed material is larger than the layer height, the printed material will be squeezed to a larger width. The increase in the width of the bead with decrease in layer height is tabulated in the Table 3 . The squeezing decreases the thickness of the bead as shown in figure 5, which is the side view of the printed material without perimeters. The thickness of the bead as shown in table 3 is observed to decrease with increase in width, as layer height is reduced. Better adhesion between the flattened layers as well as decrease in void content (data on this will be presented during the conference) are believed to the reasons for the increase in properties with decrease in layer height.

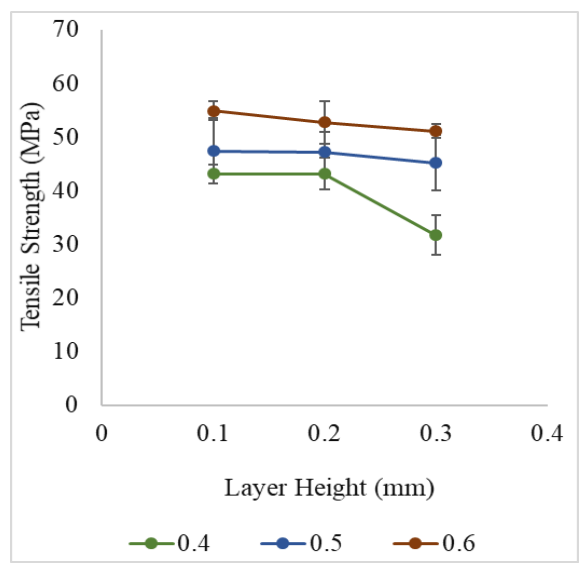

(a)

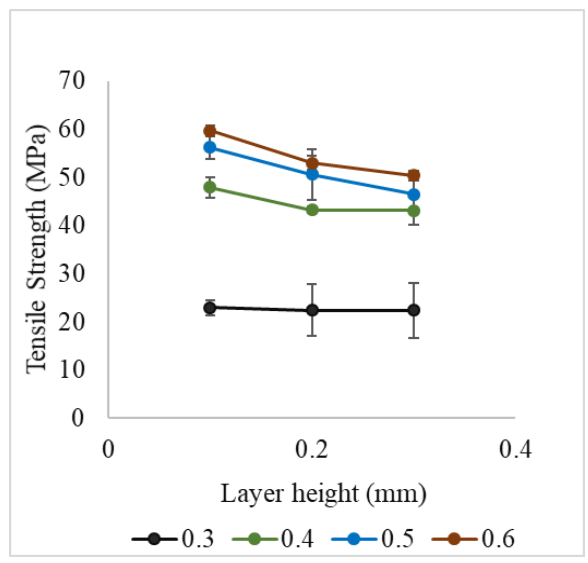

(b) 


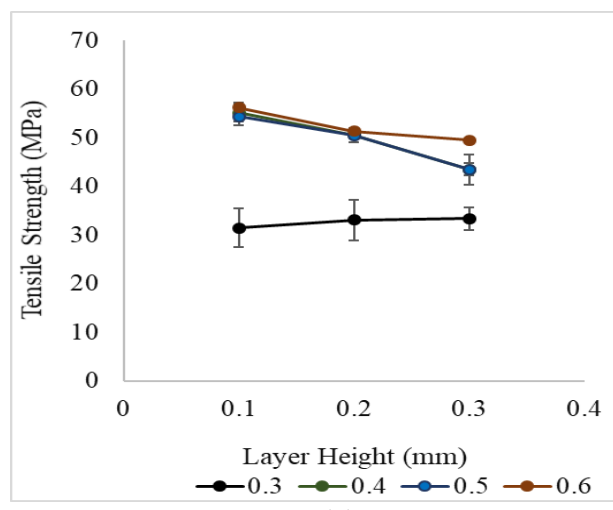

(c)

Fig 3. Effect of layer height on the tensile modulus for various nozzle diameters and print temperatures (a) $240{ }^{\circ} \mathrm{C}$ (b) $250{ }^{\circ} \mathrm{C}(\mathrm{c}) 260^{\circ} \mathrm{C}$

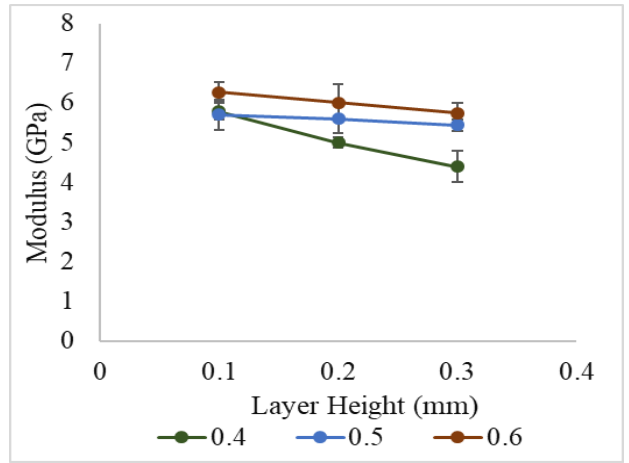

(a)

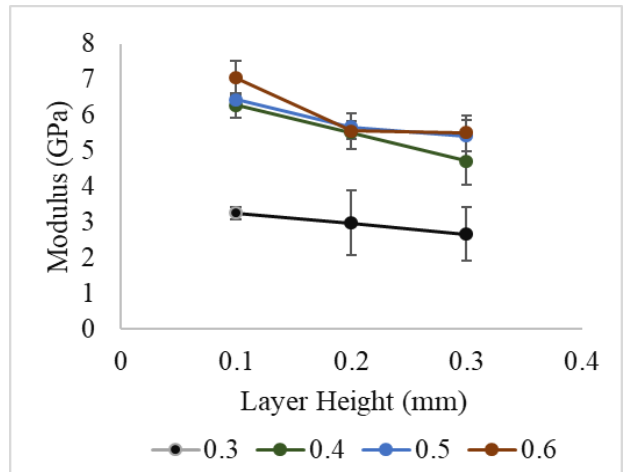

(b)

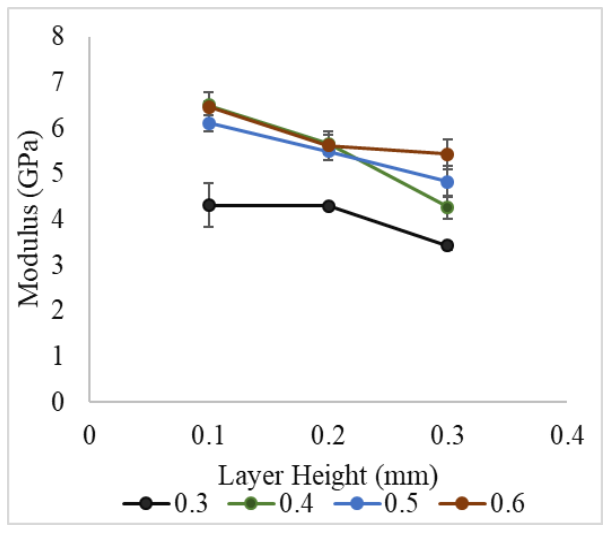

(c)

Fig 4. Effect of layer height on the tensile modulus for various nozzle diameters and print temperatures (a) $240{ }^{\circ} \mathrm{C}$ (b) $250{ }^{\circ} \mathrm{C}$ (c) $260{ }^{\circ} \mathrm{C}$

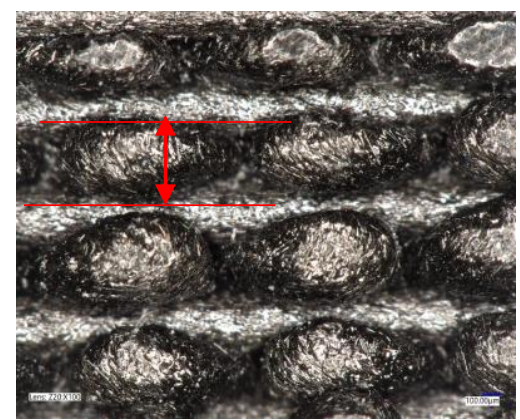

(a)

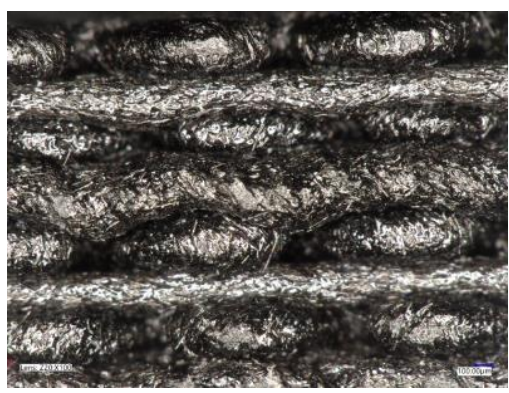

(b)

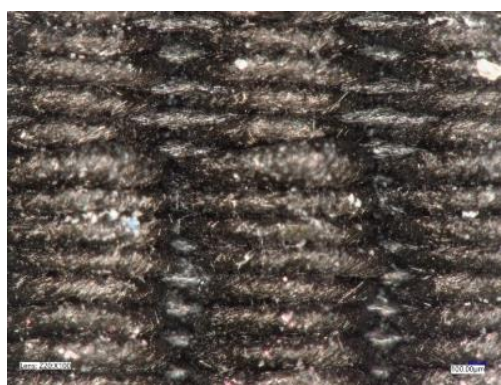

(c)

Figure 5. Side view of $0 \% 90^{\circ}$ layers printed at $250^{\circ} \mathrm{C}$ using $0.5 \mathrm{~mm}$ nozzle and various layer heights (a) $0.3 \mathrm{~mm}$ (b) $0.2 \mathrm{~mm}$ (c) $0.1 \mathrm{~mm}$ 
Table 3. Width of each bead printed at $250{ }^{\circ} \mathrm{C}$ using 0.5 nozzle

\begin{tabular}{|c|c|c|c|c|}
\hline Test & $\begin{array}{c}\text { Layer } \\
\text { Height } \\
(\mathrm{mm})\end{array}$ & $\begin{array}{c}\text { Temp } \\
\left({ }^{\circ} \mathrm{C}\right)\end{array}$ & $\begin{array}{c}\text { Bead } \\
\text { Thickness } \\
(\mu \mathrm{m})(\mathrm{S} . \mathrm{D})\end{array}$ & $\begin{array}{c}\text { Bead } \\
\text { Width } \\
(\mu \mathrm{m}) \\
(\mathrm{S} . \mathrm{D})\end{array}$ \\
\hline 1. & 0.1 & 250 & $39(10)$ & $937(28)$ \\
\hline 2. & 0.2 & 250 & $89(8)$ & $663(14)$ \\
\hline 3. & 0.3 & 250 & $163(20)$ & $558(14)$ \\
\hline
\end{tabular}

\subsection{Effect of Nozzle Diameter (ND)}

For a given layer height and print temperature, the tensile modulus and the strength generally increase with increase in N.D. At $240{ }^{\circ} \mathrm{C}$, the material could not be printed using $0.3 \mathrm{~mm}$ due to frequent clogging of the nozzle. As the temperature was increased to $250{ }^{\circ} \mathrm{C}$ and $260{ }^{\circ} \mathrm{C}$ the decrease in the viscosity enabled printing. Yet, the print had to be stopped and started again while printing a layer resulting in cold fusion at various locations of a layer. These are weak spots. Because of this, a large standard deviation was recorded for samples printed using $0.3 \mathrm{~mm}$

A significant jump in properties, observed in Figures 2 and 3 , with increase in ND is due to increase in raster width as shown in Table 4. Enhancement in bonding between layers and decrease in void content are believed to be the causes for increase in the properties with increase in ND.

Table 4 . Width of each bead printed using 0.3 layer height at $250{ }^{\circ} \mathrm{C}$

\begin{tabular}{|c|c|c|c|}
\hline Test & $\begin{array}{c}\text { Nozzle } \\
\text { Diameter } \\
(\mathrm{mm})\end{array}$ & $\begin{array}{c}\text { Layer } \\
\text { Height }\end{array}$ & $\begin{array}{c}\text { Bead Width } \\
(\mu \mathrm{m})(\mathrm{S} . \mathrm{D})\end{array}$ \\
\hline 1. & 0.3 & 0.3 & $275(22)$ \\
\hline 2. & 0.4 & 0.3 & $381(15)$ \\
\hline 3. & 0.5 & 0.3 & $558(14)$ \\
\hline 4. & 0.6 & 0.3 & $721(8)$ \\
\hline
\end{tabular}

\subsection{Effect of Extrusion Temperature}

Extrusion temperature had the minimal effect on the mechanical properties when compared to the effects of layer height and nozzle diameter. Effect of the extrusion temperature was much more evident for smaller nozzles diameters $(0.3 \mathrm{~mm}$, $0.4 \mathrm{~mm}$ ). Increasing the print temperatures from $240{ }^{\circ} \mathrm{C}$ to 260 ${ }^{\circ} \mathrm{C}$ with $0.4 \mathrm{~mm} \quad$ N.D. and $0.1 \mathrm{~mm}$ layer height, resulted in increase in the tensile strength from $43.1 \mathrm{MPa}$ to $54.1 \mathrm{MPa}$ and in the modulus from 5.78 GPa to $6.47 \mathrm{GPa}$. This can be explained as follows: with increase in temperature the viscosity decreased enabling the smoother flow and better adhesion of the composite layers. Using $0.3 \mathrm{~mm}$ N.D., it was not possible to extrude the material at $240{ }^{\circ} \mathrm{C}$. However, material started to extrude at $250{ }^{\circ} \mathrm{C}$, but unevenly resulting in poor quality. The quality improved at $260{ }^{\circ} \mathrm{C}$ for the same print parameters. The quality of samples printed for all NDs and layer height were good for $250{ }^{\circ} \mathrm{C}$ and $260{ }^{\circ} \mathrm{C}$.

\subsection{Optimized Print Parameters}

The optimal print parameters, which resulted in highest tensile modulus and strength, are $0.1 \mathrm{~mm}$ layer height, $0.6 \mathrm{~mm}$ nozzle diameter and print temperature of $250{ }^{\circ} \mathrm{C}$. The density, the tensile modulus, and the tensile strength of the specimen printed using these parameters, tabulated in Table 5, are 1.315 $\mathrm{g} / \mathrm{cm}^{3}, 59.7 \mathrm{MPa}$ and $7.03 \mathrm{GPa}$ respectively. The properties of compression molded specimens (molded at $260{ }^{\circ} \mathrm{C}$ using 2 ton pressure) are also tabulated in Table 5. Density of both specimens were measured using the pycnometer.

The density of the FDM specimen was lower than that of the compression molded specimens. Assuming that the compression molded specimens were $100 \%$ dense, the void fraction in the FDM specimen was determined to be $3 \%$. The tensile modulus and strength of the FDM specimens were 94\% and $97 \%$ of the values for compression molded specimens. It should be noted that few FDM specimens were used in compression molding. These specimens were fitted into a mold cavity with similar shape and size and were subjected to compression molding conditions. This was done to ensure same fiber orientation enabling the comparison of both specimens.

In general, fibers are never oriented in one direction in compression molded parts. Hence, the properties of specimens prepared using compression molding of PET-G/carbon filament would be lower than the those for the specimens prepared using compression molding of FDM printed material with oriented fibers. Hence, FDM of PET-G/carbon is expected to result in parts with properties equal to or better than compression molded parts, despite having a slightly lower density (due to voids).

The above results confirm that the chosen print conditions would result in best properties for the carbon fiber reinforced PET-G parts and they are likely to equal the quality and properties of a compression molded part using the same material.

Table 5. Comparison of properties of FDM printed and compression molded specimens.

\begin{tabular}{|c|c|c|c|c|}
\hline Test & $\begin{array}{l}\text { Manufacturing } \\
\text { Technique }\end{array}$ & $\begin{array}{l}\text { Density( } \\
\left.\mathrm{g} / \mathrm{cm}^{3}\right) \text {, } \\
\text { (S.D) }\end{array}$ & $\begin{array}{c}\text { Tensile } \\
\text { Strength } \\
\text { (MPa), } \\
\text { (S.D) }\end{array}$ & $\begin{array}{c}\text { Modulu } \\
\text { s (GPa), } \\
\text { (S.D). }\end{array}$ \\
\hline 1. & FDM & $\begin{array}{c}1.315 \\
(0.0018)\end{array}$ & $59.7(2.4)$ & $\begin{array}{c}7.03 \\
(0.13)\end{array}$ \\
\hline 2. & $\begin{array}{c}\text { Compression } \\
\text { Moulding }\end{array}$ & $\begin{array}{c}1.352 \\
(0.0002) \\
\end{array}$ & $\begin{array}{l}61.29 \\
(1.5) \\
\end{array}$ & $\begin{array}{c}7.5 \\
(0.48) \\
\end{array}$ \\
\hline
\end{tabular}

\section{SUMMARY}

This research focused on delineating the effect of three print process parameters on the mechanical properties of the carbon reinforced PET-G composites Layer height had the maximum impact on the mechanical properties of the printed specimen; decreasing the layer height increased the strength 
and the modulus. Increasing the nozzle diameter increased the mechanical properties of the samples. Temperature had the minimal effect. Optimized print parameter for carbon reinforced PET-G are $0.1 \mathrm{~mm}$ layer height, $0.6 \mathrm{~mm}$ nozzle diameter and print temperature of $250{ }^{\circ} \mathrm{C}$. Specimens printed using the optimal print parameters resulted in tensile modulus and tensile strength that were $94 \%$ and $97 \%$ of those for compression molded part, despite having $3 \%$ void content.

\section{ACKNOWLEDGMENT}

The authors would like to acknowledge the funding from NSERC, Canada. The first author would like to acknowledge with gratitude the Mitacs and UMGF funding.

\section{REFERENCES}

[1] Crump, S. S. inventor., Stratasys, Inc., "Apparatus and method for creating three- dimensional objects". United States Patent US Patent 5,121,329, 1992.

[2.] Ready, S., Endicott, F., Whiting, G.L., Ng, T.A., Chow, E.M., Lu, J. “3D printed electronics" In Proceedings of the International Conference on Digital Printing Technologies, Seattle, WA, USA, 2013.

[3.] Ahmed, NA., Page, JR. "Manufacture of an Unmanned Aerial Vehicle (UAV) for Advanced Project Design Using 3D Printing Technology". Applied Mechanics and Materials 2013

[4.] Murphy, S.V., Atala, A., "3D bioprinting of tissues and organs". Nat. Biotechnol. 2014

[5.] Seliktar, D., Dikovsky, D., Napadensky, E., "Bioprinting and tissue engineering: Recent advances and future perspectives". Isr. J. Chem. 2013, 53, 795-804.

[6.] Richardson, M., Haylock, B., Designer/maker, The rise of additive manufacturing, domestic-scale production and the possible implications for the automotive industry. Comput.-Aided Des. Appl. PACE 2012.

[7.] Bos, F., Wolfs, R., Ahmed, Z., Salet, T., "Additive manufacturing of concrete in construction: Potentials and challenges of 3D concrete printing". Virtual Phys. Prototyp. 2016.

[8] Wu, P., Wang, J., Wang, X., "A critical review of the use of 3-D printing in the construction industry". Autom. Constr. 2016.

[9] Hager, I., Golonka, A., Putanowicz, R., "3D printing of buildings and building components as the future of sustainable construction", Procedia Eng. 2016
[10] Perkins, I., Skitmore, M., "Three-dimensional printing in the construction industry: A review”. Int. J. Constr. Manag. 2015.

[11] Melnikova, R., Ehrmann, A., Finsterbusch, K., "3D printing of textilebased structures by Fused Deposition Modelling (FDM) with different polymer materials". In IOP Conference Series: Materials Science and Engineering, Volume 62 Bristol, UK, 2014.

[12] Grimmelsmann, N., Kreuziger, M., Korger, M., Meissner, H., Ehrmann, A., "Adhesion of 3D printed material on textile substrates". Rapid Prototyp. J. 2018

[13] Hudson, S.E.," Printing teddy bears: A technique for 3D printing of soft interactive objects". In Proceedings of the SIGCHI Conference on Human Factors in Computing Systems, Toronto, ON, Canada, 2014.

[14] Dawoud, Michael., Taha, Iman., J. Ebeid, Samy., "Mechanical behavior of ABS: An experimental study using FDM and injection moulding techniques", Journal of Manufacturing Processes 21 (2016).

[15] Measuring VOC and nanoparticle emissions during fused filament fabrication Eastman Chemical Company,2014.SDS:Eastman Amphora 3D PolymerAM1800.

[16] Abouzaid, Khaoula., Guessasma, Sofiane., Belhabib, Sofiane., Bassir, David., Chouaf, Abdelkrim., "Printability of co-polyester using fused

[17] Tekinalp, H. L., Kunc, V., Velez-Garcia, G. M., Duty, C. E., Love, L. J., Naskar, A. K., Blue, C. A., and Ozcan, C., "Highly oriented carbon fiber polymer composites via additive manufacturing". Compos Sci Technol 2014.

[18] Ferreira, R.T.L.; Amatte, I.C.; Dutra, T.A.; Bürger, D., "Experimental characterization and micrography of 3D printed PLA and PLA reinforced with short

[19] B.G. Compton, J.A. Lewis, "3D-printing of lightweight cellular composites", Adv. Mater. 26, 2014.

[20] Brenken, Bastian., Barocioa, Eduardo., Favaloroa, Anthony., Kunc, Vlastimil., R. Byron Pipes, "Fused filament fabrication of fiber-reinforced polymers: A review", Additive Manufacturing Volume 21, May 2018.

[21] MS, Hossain., D, Espalin., J, Ramos. "Improved mechanical properties of fused deposition modeling manufactured parts through build parameter modifications". J Manuf Sci E 2014; 136: 061002-1-061002-12

[22] Ning, Fuda., Cong, Weilong., Hu, Yingbin., and Wang, Hui., "Additive manufacturing of carbon fiber-reinforced plastic composites using fused deposition modeling: Effects of process parameters on tensile properties", Journal of Composite Materials 2017, Vol. 51(4) 451-462.

[23] ASTM D638-14, "Standard Test Method for Tensile Properties of Plastics", ASTM International, West Conshohocken, PA, 2014, www.astm.org 